\title{
Lornoxicam drug - a new study of thermal degradation under oxidative and pyrolysis conditions using the thermoanalytical techniques, DRX and LC-MS/MS
}

A.C.S. Carvalho ${ }^{a}$, G.A.C. Zangaro ${ }^{a}$, R.P. Fernandes ${ }^{a}$, B. Ekawa ${ }^{a}$, A.L.C.S. Nascimento ${ }^{\mathrm{a}, \mathrm{b}}$, B.F. Silva $^{\mathrm{a}}$, G.P. Ashton ${ }^{\mathrm{b}}$, G.M.B. Parkes ${ }^{\mathrm{b}}$, M. Ionashiro ${ }^{\mathrm{a}}$, F.J. Caires ${ }^{\mathrm{a}, \mathrm{c}^{*}}$.

${ }^{a}$ Universidade Estadual Paulista (Unesp), Instituto de Química, Araraquara, SP, Brazil.

${ }^{\text {b}}$ Thermal Methods Research Unit, Department of Chemistry, University of Huddersfield, Queensgate, Huddersfield HD1 3DH, United Kingdom.

'Universidade Estadual Paulista (Unesp), Faculdade de Ciências, Bauru, SP, Brazil.

\begin{abstract}
In the present work, the thermal behavior of Lornoxicam drug was studied under oxidizing (air) and pyrolysis $\left(\mathrm{N}_{2}\right)$ atmospheres using simultaneous thermogravimetry and differential scanning calorimetry (TG-DSC), differential scanning calorimetry (DSC), Hot Stage Microscopy (HSM) and Evolved Gas Analysis (EGA) in the form of thermogravimetry coupled to infrared spectroscopy (TG-FTIR) and mass spectrometry (TG-MS). The thermal degradation product formed at different temperatures were examined using liquid chromatography coupled to mass spectrometry (LC-MS) and Powder X-Ray Diffraction (PXRD). The thermal study showed that the drug does not melt, partially amorphized on heating, it is thermally stable to $205{ }^{\circ} \mathrm{C}$ and undergoes thermal decomposition in two overlapping mass loss steps. Furthermore, the DSC and MS techniques suggest that thermal degradation processes are very complex, which occur with the release of gaseous products $\mathrm{HCN}, \mathrm{SO}_{2}, \mathrm{COS}, \mathrm{CO}_{2}, \mathrm{~N}_{2} \mathrm{O}$ and $\mathrm{CO}$ and formation of three intermediate in the thermal residue.
\end{abstract}

Keywords: Lornoxicam; Thermal degradation; EGA; LC-MS/MS; HSM.

${ }^{*}$ Corresponding author.

E-mail address: flavio.caires@unesp.br (F. J. Caires) 


\section{INTRODUCTION}

Lornoxicam (6-Chloro-4-hydroxy-2-methyl-N-2-pyridinyl-2H-thieno[2,3-e]-1,2thiazine-3-carboxamide 1,1-dioxide, $\mathrm{C}_{13} \mathrm{H}_{10} \mathrm{ClN}_{3} \mathrm{O}_{4} \mathrm{~S}_{2}$, Fig.1) is a non-steroidal antiinflammatory drug (NSAID) that belongs to the "oxicam" class, which presents analgesic, anti-inflammatory and antipyretic properties [1,2,3]. It is used in musculoskeletal and joint disorders such as osteoarthritis and rheumatoid arthritis. It is also used in the treatment of conditions such as postoperative pain and has been demonstrated to be as effective as morphine [4]. It is a yellow, amphiprotic crystalline compound with a molecular weight of $371.81 \mathrm{~g} \mathrm{~mol}^{-1}$ that exists as a zwitterion in the solid state $[4,5]$.

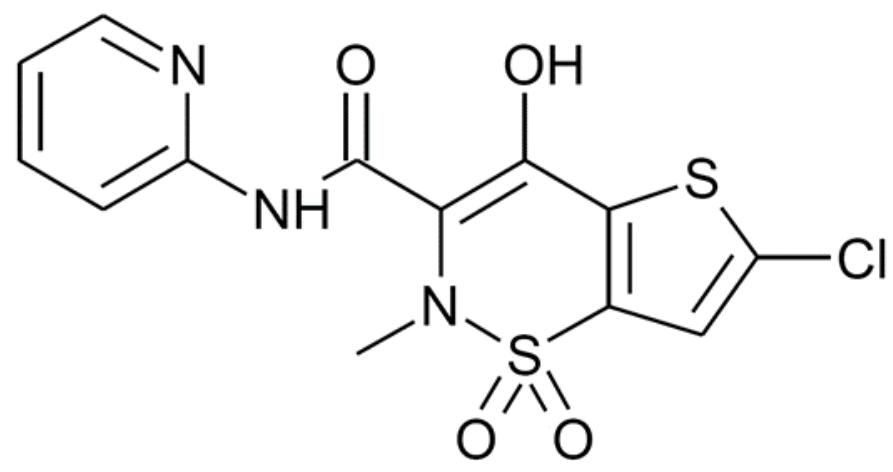

Fig. 1: Chemical structures of Lornoxicam.

The thermal analysis is widely used by the pharmaceutical industries for quality control of drugs because it can provide important information relating to thermal stability, degradation and purity determination of drug substances, the physicochemical characteristics of natural raw material, crystal forms and polymorphic stability, drugexcipient compatibility studies, correlation of drug components, among others [6-9]. In addition, identifying the thermal degradation products may support studies of forced degradation of the drug [10]. Thermal analysis coupled with techniques such as mass spectrometry and infrared spectroscopy has been widely used to understand the mechanisms of thermal decomposition, allowing the assignment of the products produced in the reactions [7-12].

The thermal decomposition of Lornoxicam in pyrolytic and oxidative atmosphere has been previously reported [5, 13-19]. However, the thermal degradation products have not been previously investigated, and the thermal degradation mechanism of this drug is unknown. Thus, the main objectives of this study were to conduct a detailed study of the thermal behavior in an oxidizing and inert atmosphere and to identify the formed products during the thermal decomposition steps. For this, investigations of the thermal behavior 
of Lornoxicam in nitrogen and air atmospheres were undertaken using simultaneous thermogravimetry and differential scanning calorimetry (TG-DSC), differential scanning calorimetry (DSC), Hot Stage Microscopy (HSM), evolved gas analysis (EGA by TGFTIR and TG-MS). The thermal residues from Lornoxicam heated to different temperatures $\left(180{ }^{\circ} \mathrm{C}, 220^{\circ} \mathrm{C}\right.$ and $\left.235^{\circ} \mathrm{C}\right)$ were examined using liquid chromatography mass-spectrometry (LC-MS) and Powder X-Ray Diffraction (PXRD).

\section{MATERIAL AND METHODS}

\subsection{Materials}

Lornoxicam (99.98\% purity) was donated by the Biolab Pharma, São PauloBrazil.

\subsection{Thermal Analysis (TA)}

Simultaneous thermogravimetry and differential scanning calorimetry (TG-DSC) curves were obtained under dry air and $\mathrm{N}_{2}$ atmospheres with a flow rate of $50 \mathrm{~mL} \mathrm{~min}^{-1}$ using TG-DSC 1 (Mettler-Toledo). Samples weighing about $10 \mathrm{mg}$ were placed in alumina crucibles and heated at a rate of $10^{\circ} \mathrm{C} \mathrm{min}^{-1}$ to $800{ }^{\circ} \mathrm{C}$.

DSC curves were obtained under dry air and $\mathrm{N}_{2}$ atmospheres with a flow rate of $50 \mathrm{~mL} \mathrm{~min}^{-1}$ using a DSC Q10 (TA Instruments). Samples weighing about $2 \mathrm{mg}$ were sealed in aluminum crucibles with perforated lids and heated at a rate of $10{ }^{\circ} \mathrm{C} \min ^{-1}$ to $225^{\circ} \mathrm{C}$.

The DSC-microscopy analysis was obtained using a Mettler Toledo DSC 1 stare system coupled to an OLYMPUS digital camera, model SC 30, which incorporates a 3.3megapixel CMOS sensor and an optical subassembly mechanic Navitar 1-6232D with 6.5 $\mathrm{x}$ zoom. The experimental conditions were similar to those used to obtain the DSC curve.

The detection of the gaseous products evolved during the thermal decomposition was carried out using a TG-DSC 1 (Mettler-Toledo) coupled to a FTIR spectrophotometer (Nicolet) with gas cell and DTGS ZnSe detector. The furnace and heated gas cell $\left(250^{\circ} \mathrm{C}\right)$ were coupled through a heated $\left(225^{\circ} \mathrm{C}\right) 120 \mathrm{~cm}$ stainless steel transfer line with diameter of $3.0 \mathrm{~mm}$ with a flow of dry air or $\mathrm{N}_{2}$ at rate of $50 \mathrm{~mL} \mathrm{~min}^{-1}$. The FTIR spectra were recorded in the 4000-675 $\mathrm{cm}^{-1}$ wavelength range, at a resolution of $4 \mathrm{~cm}^{-1}$ and with 
16 scans per spectrum. The identification of the gaseous products was based on the reference spectra available in the spectrometer's software (OMNIC 8.0) and literature data. In addition TG-DSC-FTIR, additional analysis of product gases was undertaken with TG-MS. The system was comprised of a SDTATGA1150 (Mettler-Toledo) coupled to HPR20 Quadrupole MS (Hiden). Gaseous analytes were transferred from the TG's outlet to the MS's inlet via a heated capillary line held at $250{ }^{\circ} \mathrm{C}$ under separate atmospheres of air and nitrogen $\left(60 \mathrm{~mL} \mathrm{~min}^{-1}\right)$. The mass spectrometer was operated in selected ion monitoring mode focusing on key ions apparent in the initial full mass screening of lornoxicam. The mass spectrometer was operated in EI mode with the source voltage set to $70 \mathrm{eV}$ using a SEM detector, an accumulation time of $50 \mathrm{~ms}$ was used. Samples weighing approximately $5 \mathrm{mg}$ were placed in alumina crucibles and heated between 30 and $800{ }^{\circ} \mathrm{C}$ at a rate of $10{ }^{\circ} \mathrm{Cmin}^{-1}$.

Hot-stage microscopy measurements used a HSM-5 (Stanton-Redcroft) coupled with stereoscopic microscope (Leica) with a 5 mega pixel digital imager (Celestron) for image capture and an optical sensor to measure the reflected light intensity (RLI) throughout an experiment. Sample masses of $5 \mathrm{mg}$ were placed in $6 \mathrm{~mm}$ alumina crucibles and heated at a rate of $10{ }^{\circ} \mathrm{C} \mathrm{min}^{-1}$ to $800{ }^{\circ} \mathrm{C} \mathrm{min}^{-1}$ under air and nitrogen.

\subsection{LC-MS/MS}

LC-MS/MS analysis were conducted on a 1200 Agilent Technologies LC chromatograph coupled to an AB SCIEX Instruments 3200QTRAP mass spectrometer. LC separation was achieved using a core shell C-18 reversed phase as the stationary phase $\left(150 \mathrm{~mm} \times 4.6 \mathrm{~mm}, 5 \mu\right.$, from Phenomenex $\left.{ }^{\circledR}\right)$ and a mixture of water $\left(\mathrm{H}_{2} \mathrm{O}\right)$ and acetonitrile $(\mathrm{MeCN})$ containing $0.1 \%$ formic acid $(\mathrm{v} / \mathrm{v})$ as the mobile phase at $1 \mathrm{~mL} \cdot \mathrm{min}^{-1}$ using a gradient program: $0-0.5$ minutes $(10 \% \mathrm{MeCN}), 0.5-10$ minutes $(10-90 \% \mathrm{MeCN}), 10-11$ minutes $(90 \% \mathrm{MeCN}), 11-11.5$ minutes $(10 \% \mathrm{MeCN})$ and 11.5-15 minutes (10\% MeCN). The injection volume was $20 \mu \mathrm{L}$ and column temperature was $35^{\circ} \mathrm{C}$.

The intermediate compounds formed during the Lornoxicam degradation were determined by LC-MS/MS. MS measurements were operated in a positive mode, with a TurboIonSpray ${ }^{\circledR}$ probe. A special software, Lightsight ${ }^{\circledR} 2.3$ (Nominal Mass Metabolite ID Software, AB SCIEX), was used to investigate all possible intermediates. The application of the software was performed using the ionization and fragmentation parameters optimized for the initial compound; these parameters were obtained by direct infusion at 
a rate of $10 \mu \mathrm{L} \mathrm{min}{ }^{-1}$ of the standard Lornoxicam solution (500 $\mu \mathrm{g} . \mathrm{L}^{-1}$ ) in water:acetonitrile containing $0.1 \%$ of formic acid $(1: 1, v / v)$. The MS parameters were: curtain gas at $20 \mathrm{psi}$, ion spray at $5500 \mathrm{~V}$, gases 1 and 2 at $50 \mathrm{psi}$, temperature of $600{ }^{\circ} \mathrm{C}$, declustering potential of $36 \mathrm{~V}$, entrance potential of $7.5 \mathrm{~V}$, and with the interface heater turned on. Optimized selected reaction monitoring (SRM) and full-scan experiments were automatically performed by the LightSight ${ }^{\circledR} 2.3$ software. Different kinds of reactions were investigated, such as oxidation, hydroxylation, reduction, $\mathrm{C}-\mathrm{C}$ bond cleavage, and others. All MS/MS experiments obtained were combined to fragmentation experiments. The LC analysis conditions for the MS measurements were those described earlier.

The samples used in the LC-MS/MS analysis were obtained using TG-DSC 1 (Mettler-Toledo). Samples weighing about $10 \mathrm{mg}$ were placed in alumina crucibles and heated at a rate of $10^{\circ} \mathrm{C} \mathrm{min}-1$ to different temperatures $\left(180{ }^{\circ} \mathrm{C}, 220^{\circ} \mathrm{C}\right.$ and $\left.235^{\circ} \mathrm{C}\right)$.

\subsection{Powder X-Ray diffraction}

Powder X-Ray Diffraction (PXRD) pattern were obtained by using a MiniFlex $600 \mathrm{X}$-ray diffractometer (Rigaku Corporation) employing $\mathrm{CuK} \alpha$ radiation $(\lambda=1.54056$ $\AA$ ) with setting of $40 \mathrm{kV}$ and $30 \mathrm{~mA}$. The samples were analyzed from $5^{\circ}$ to $50^{\circ}(2 \theta)$ with $10^{\circ} \mathrm{min}^{-1}$ and a step size of 0.04 .

The samples preparation for PXRD analysis was similar to that described in the topic 2.3 .

\section{RESULTS AND DISCUSSION}

\subsection{TG/DTG-DSC}

The simultaneous TG, DTG and DSC curves of Lornoxicam in dynamic dry air and nitrogen atmospheres are shown in Fig. 2 ( $a$ and b), respectively. These curves show that the drug is thermally stable up to $205{ }^{\circ} \mathrm{C}$ (air and $\mathrm{N}_{2}$ ) and undergoes thermal decomposition in two mass loss steps, as suggested by the DTG curve.

The DTG curve (Fig. 2) suggests that the thermal decomposition mechanism in air occurs in more than one stage, as previously seen in the degradation of other oxicam drugs $[6,20]$. In both atmospheres an initially sharp, exothermic, mass loss occurs over the range of 205 to $360{ }^{\circ} \mathrm{C}$ with a $\Delta \mathrm{m}$ of $63.02 \%$ (air) and $63.97 \%\left(\mathrm{~N}_{2}\right)$. This interpretation is in disagreement with many previous workers who attributed this thermal event to fusion of the drug [15-19]. 
The sample in air undergoes a further mass loss over the range $360-680{ }^{\circ} \mathrm{C}$ $\left(\Delta \mathrm{m}_{2}=38.56 \%\right)$ also with an associated exotherm attributed to complete oxidation of remaining material. In contrast, the sample in nitrogen only shows a small, broad, mass loss above $360{ }^{\circ} \mathrm{C}\left(\Delta \mathrm{m}_{2}=15.34 \%\right.$ at $\left.800{ }^{\circ} \mathrm{C}\right)$ without any thermal event in the DSC curve. This is attributed to the slow pyrolysis of the solid degradation products produced in the first step.

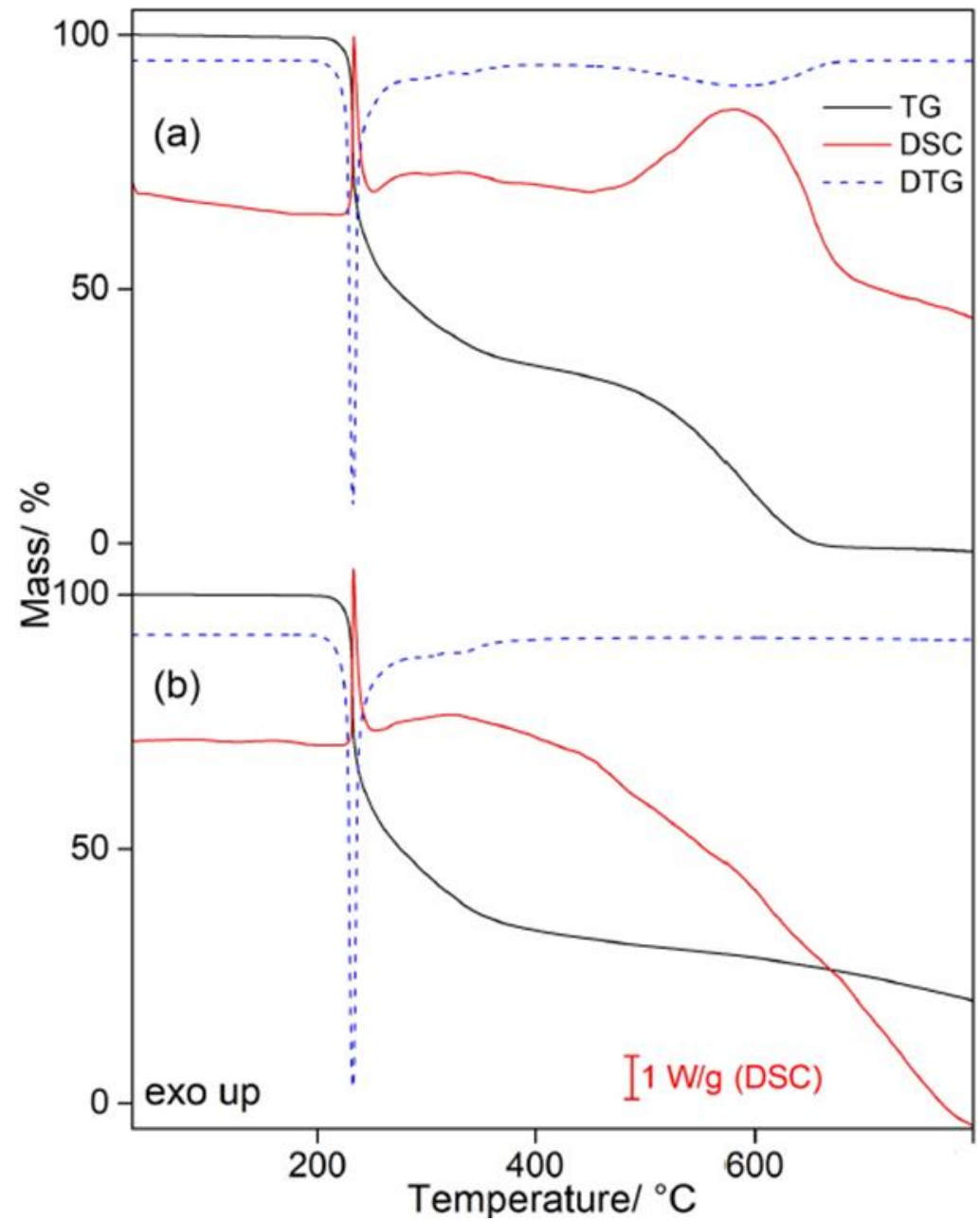

Fig.2: TG/DTG-DSC obtained in air (a) and in $\mathrm{N}_{2}$ (b) atmospheres of Lornoxicam.

\subsection{DSC, DSC-microscopy, HSM and PXRD}

The DSC curves obtained in air and $\mathrm{N}_{2}$ atmospheres are shown in Fig. 3a. These curves do not show any significant thermal events up to $200{ }^{\circ} \mathrm{C}$ when the onset of the exothermic degradation, revealed in the TG-DSC studies, is seen. The DSC curve obtained under air atmosphere shows a baseline deviation at approximately $112^{\circ} \mathrm{C}$, very similar to that observed for glassy transitions of amorphous materials [21]. However, this does not seem to be the case, since the material is crystalline up to that temperature and this effect is not observed in $\mathrm{N}_{2}$ atmosphere, which suggests that this deviation is related 
to experimental issues. In addition, the atmosphere employed does not show any influence on the thermal behavior of this compound up to $220^{\circ} \mathrm{C}$, again in accordance with the TG-DSC curves.

To investigate any low energy processes that may not be observable using DSC the drug was analyzed using DSC-microscopy, HSM and PXRD. HSM and DSCmicroscopy allow the detection of physical processes through optical changes in the sample during heating. Fusion, crystalline transitions, decomposition and others events can be observed in the images obtained by HSM [22]. Fig. 3b shows the reflected light intensity (RLI) of the drug obtained in air atmosphere plotted as a function of temperature with selected micrographs. The RLI curve shows a gradual change in light intensity up to $170{ }^{\circ} \mathrm{C}$. This corresponds to a clear colour change from yellow to orange as seen in associated micrographs $\mathrm{A}$ and $\mathrm{B}$. The cause of this process is unknown but there is no indication of any fusion. The light intensity falls sharply in the region 170 to $200{ }^{\circ} \mathrm{C}$ corresponding to a colour change from orange to brown (micrograph $\mathrm{C}$ ) as the drug decomposes. Fig. S1 and S2 presents HSM micrographs obtained in air and nitrogen atmospheres. In both atmospheres it was observed that the drug does not melt, as also observed in the video (available online) obtained by DSC-microscopy, where it is evident that the sample undergoes thermal degradation (browning and material loss) and the remaining material becomes liquid. 
(a)
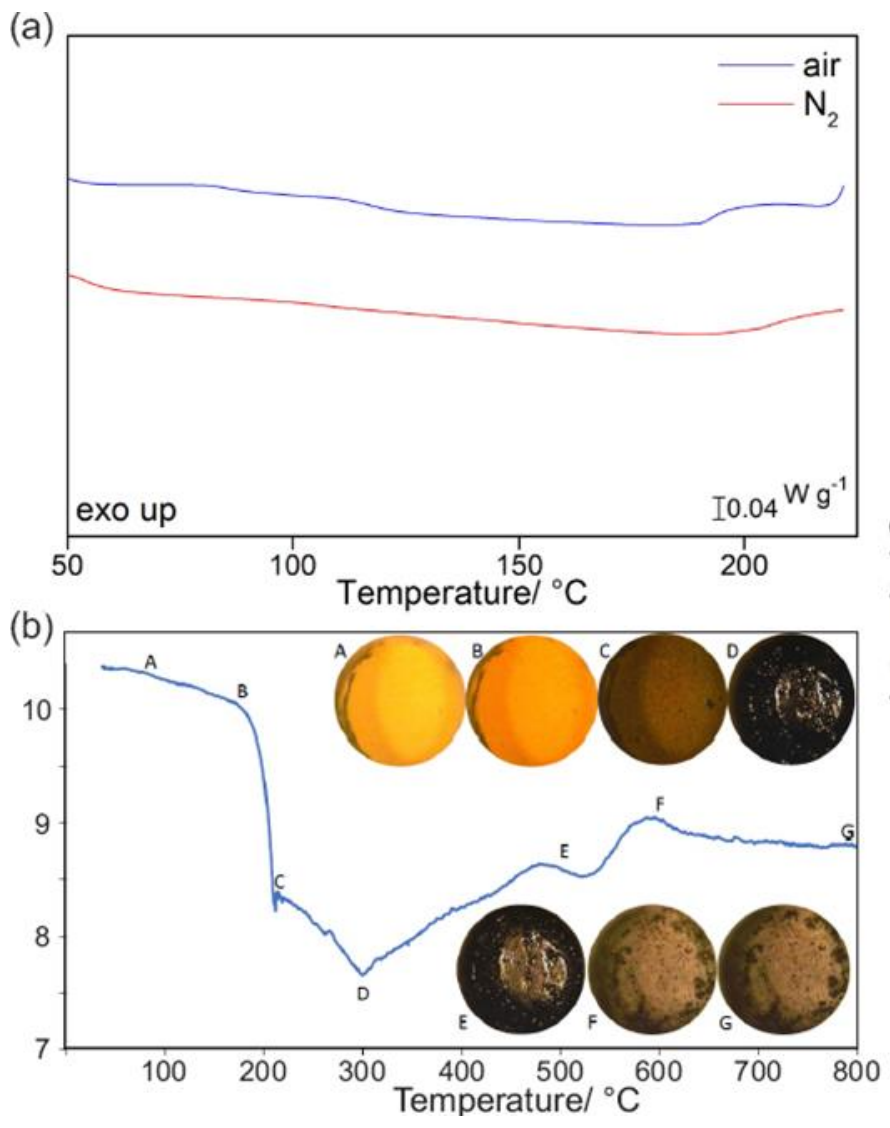

(c)

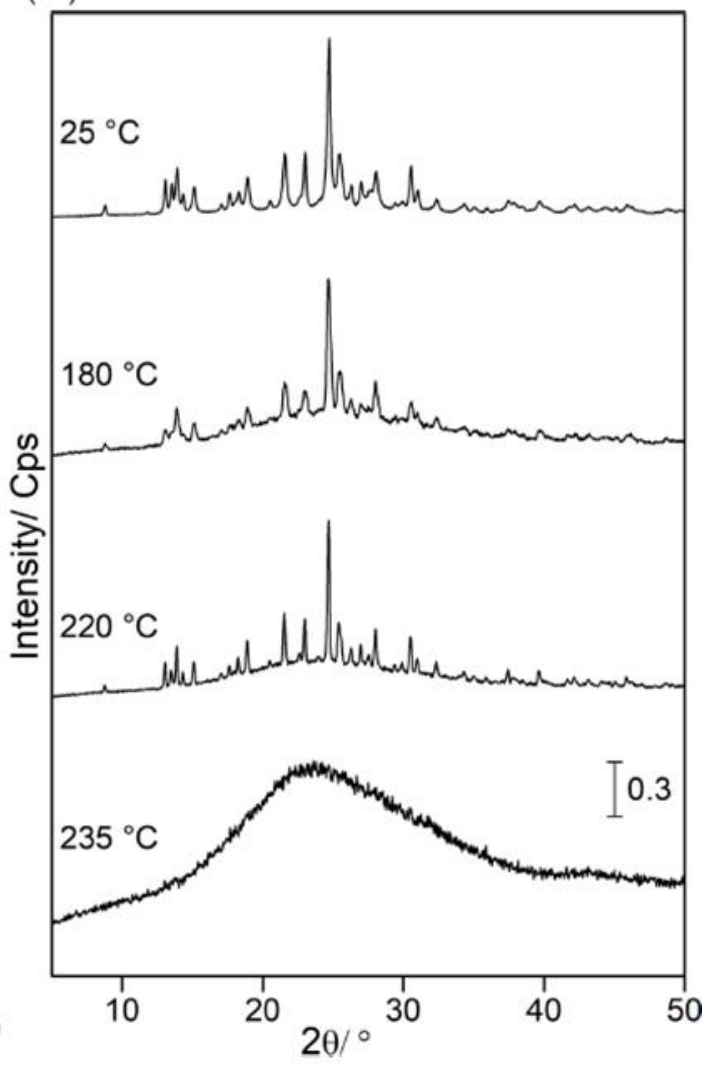

Fig. 3: DSC curve in air and $\mathrm{N}_{2}$ atmospheres (a), RLI graph (b) and PXRD (c) of Lornoxicam.

The PXRD diffractograms of samples heated to different temperatures are shown in Fig. 3c. The diffractogram obtained at room temperature $\left(25^{\circ} \mathrm{C}\right)$ shows that the acquired drug is crystalline, with no evidence of amorphous content, and corresponds to the polymorph II [3]. The diffractogram at $180^{\circ} \mathrm{C}$ shows a partial amorphization process, indicated by the appearance of a subtle diffraction halo superimposed on the diffraction peaks. The sample heated to $220^{\circ} \mathrm{C}$, shows a decrease in crystallinity, when compared to Lornoxicam $25{ }^{\circ} \mathrm{C}$, although some peaks are still observed, indicating that the material still presents a certain crystallinity resulting from the presence of non-degraded Lornoxicam. After heating at $235^{\circ} \mathrm{C}$, the product material has an amorphous character, which is attributed to the degradation products formed.

To better understand what occurs as Lornoxicam is heated, these same residues obtained from heating were characterized by LC-MS as discussed in section 3.4.

\subsection{Evolved Gas Analyses by TG-FTIR and TG-MS in oxidative and pyrolysis conditions}


The TG-FTIR data is shown in Fig. 4. The Gram Schmidt (GS) profiles suggest at least two overlapping mass loss steps, in agreement with the TG/DTG curves. The first peak is very similar for both atmospheres ((a) air and (b) $\mathrm{N}_{2}$ ) and is associated with the formation of the same gaseous products $\left(\mathrm{CO}_{2}, \mathrm{COS}, \mathrm{SO}_{2}, \mathrm{HCN}\right)$, suggesting that the thermal degradation mechanism is independent of the atmosphere used. However, the GS profiles suggest that the second step of mass loss is significantly influenced by the atmosphere used, as indicated previously.

A more detailed inspection of the GS profile of the sample under air shows a small peak around $360{ }^{\circ} \mathrm{C}$, the same temperature range of the second peak observed in the GS profile for the sample under $\mathrm{N}_{2}$, which suggests that processes similar to those observed under pyrolysis conditions are predominant at the beginning of the second mass loss step (Fig. 4a, overlapping region), a transition region. However, with increasing temperature, the oxidative processes become predominant, which results in the second peak in the GSair curve associated with the oxidation of all organic matter present. This can also be confirmed by the greater variety and quantity of gaseous products released in this step for the sample under air $\left(\mathrm{CO}, \mathrm{CO}_{2}, \mathrm{~N}_{2} \mathrm{O}, \mathrm{COS}, \mathrm{SO}_{2}\right)$ compared to those released by the sample under $\mathrm{N}_{2}\left(\mathrm{CO}_{2}\right.$ and $\left.\mathrm{SO}_{2}\right)$.

A detailed analysis was performed of the chemigrams [23] generated from the integrated absorbance over specific wavelength ranges intended to show the concentration of a particular species present in the accumulated spectra. These chemigrams were plotted together with the TG curves (Fig. S3 and S4), which facilitates the comparison of the gaseous products released with the mass loss steps. Analysis of the results suggests that the first step of thermal decomposition in air atmosphere involves the release of $\mathrm{CO}_{2}, \mathrm{SO}_{2}, \mathrm{COS}$ and a small amount of $\mathrm{HCN}$. In the second step it is possible to observe the formation of $\mathrm{SO}_{2}$ again along with $\mathrm{CO}_{2}$, probably due to the high temperature together with the oxidizing atmosphere, stemming from the decomposition of material. In this step, the release of $\mathrm{CO}$ and $\mathrm{N}_{2} \mathrm{O}$ is still observed, however due to low intensity the signal of these bands in the spectrum is suppressed by $\mathrm{CO}_{2}$ band. In the pyrolytic atmosphere, a lot of $\mathrm{CO}_{2}$ were evolved in the first step of thermal degradation, a small amount of $\mathrm{HCN}, \mathrm{SO}_{2}$ and $\mathrm{COS}$ were observed as well. In the second step only $\mathrm{COS}$ and a small amount of $\mathrm{SO}_{2}$ were observed as gaseous products. 

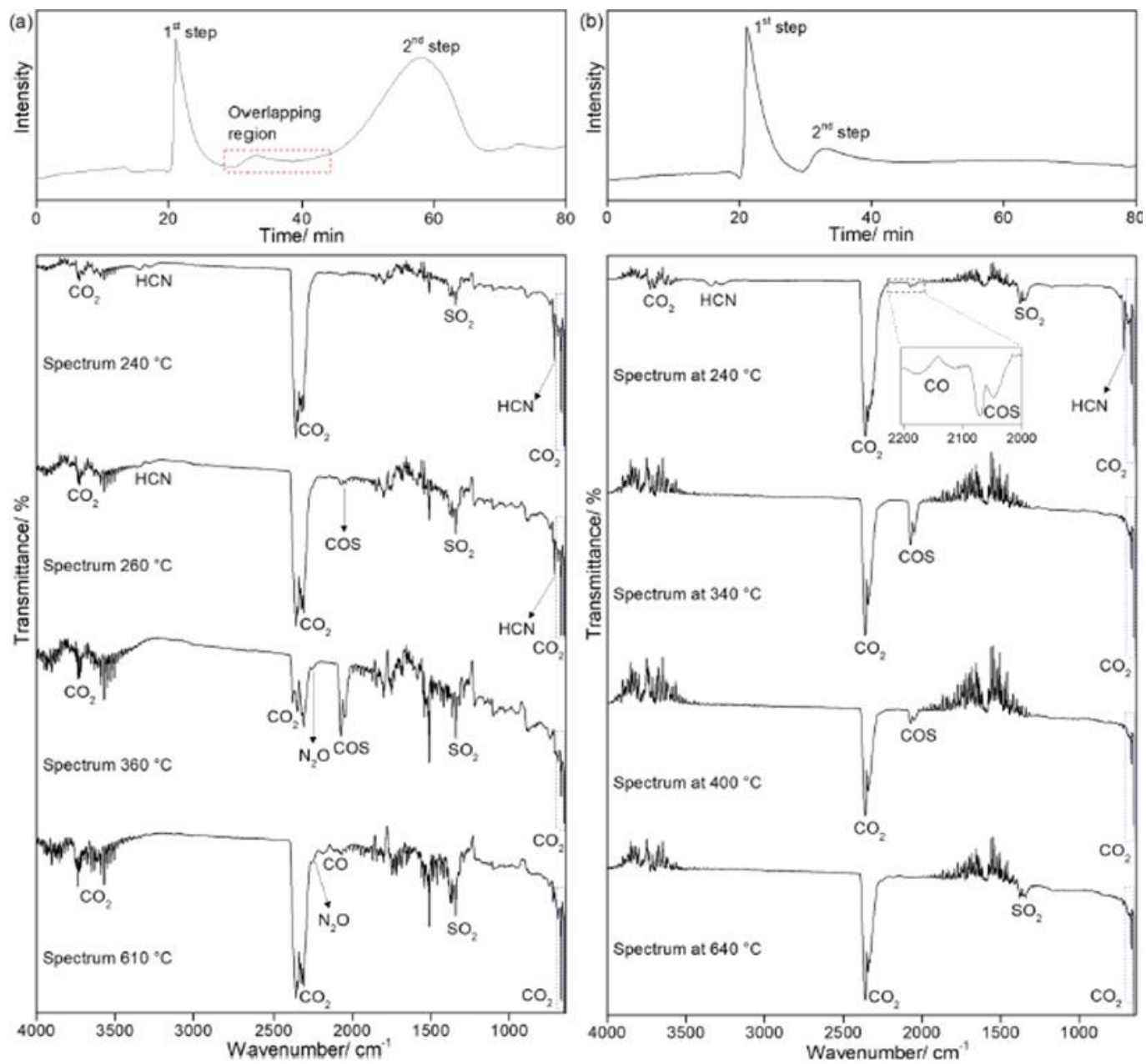

Fig. 4: Gram-Schmidt curve and IR spectra of gaseous products evolved during the decomposition of the Lornoxicam in air (a) and $\mathrm{N}_{2}$ (b).

The mass spectra obtained by TG-MS under oxidizing and pyrolysis conditions are shown in Fig. 5. The main gaseous products identified were $\mathrm{HCN}(\mathrm{m} / z 27), \mathrm{CO}_{2}$ and/or $\mathrm{N}_{2} \mathrm{O}(\mathrm{m} / \mathrm{z} 44), \operatorname{COS}(\mathrm{m} / \mathrm{z}, 60)$ and $\mathrm{SO}_{2}(\mathrm{~m} / \mathrm{z} 64)$. It is interesting to note that in $\mathrm{N}_{2}$ atmosphere, despite obtaining a fragment with a mass of $44 \mathrm{Da}$, which could correspond to the formation of $\mathrm{N}_{2} \mathrm{O}$ and/or $\mathrm{CO}_{2}$, the presence of $\mathrm{N}_{2} \mathrm{O}$ gas was not observed by TGFTIR, which indicates that this signal corresponds only to the release of $\mathrm{CO}_{2}$ from the pyrolysis of Lornoxicam.

In addition, in agreement with the results obtained by TG-FTIR, the first and the beginning of the second stage of mass loss is little influenced by the atmosphere used, presenting a similar profile of release of gaseous products. On the other hand, with increasing temperature, oxidative processes become predominant in air atmosphere, leading to a significant increase of $\mathrm{CO}_{2}$ and $\mathrm{SO}_{2}$ release, which is not observed in an inert 
atmosphere, where pyrolysis processes are responsible for the slow loss of mass on the TG curve.

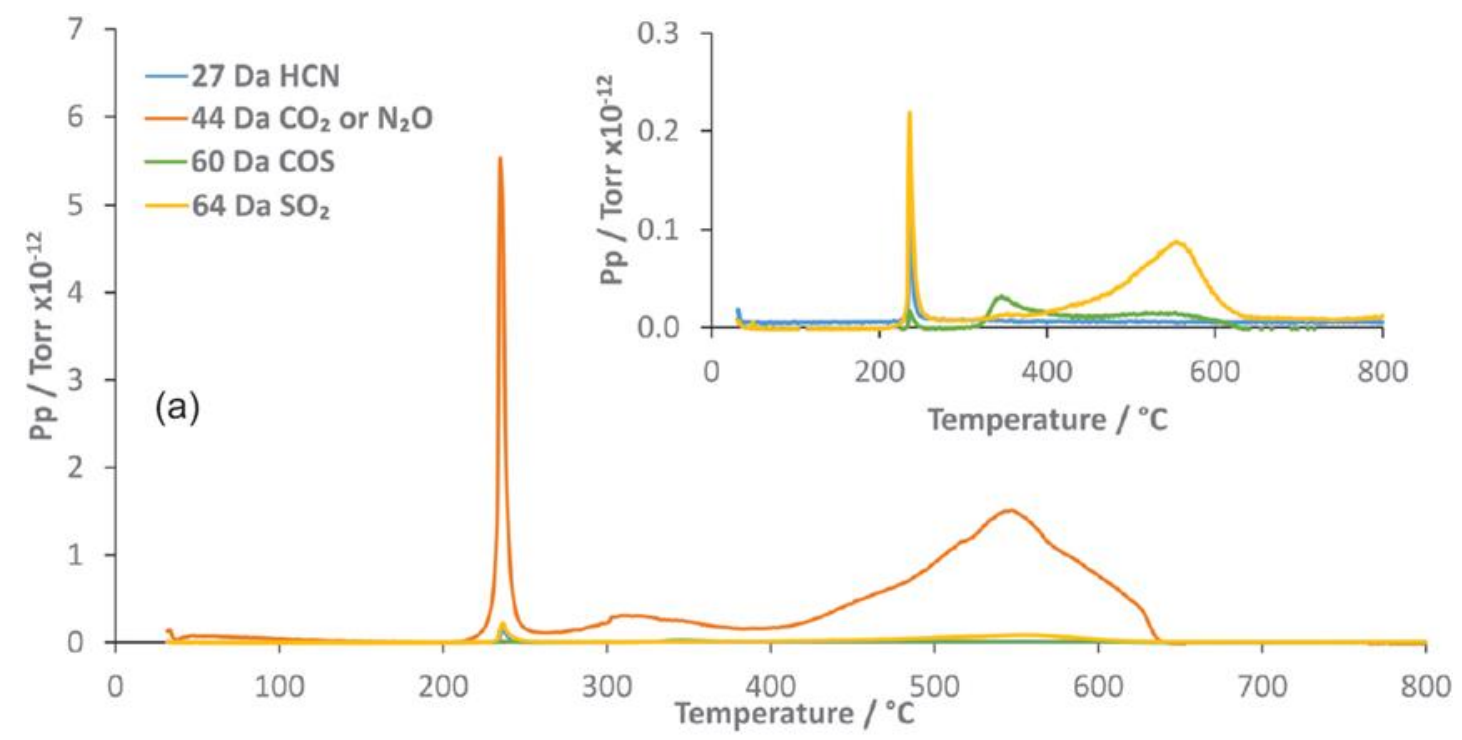

Thus, through the comparison of the results obtained by the coupled techniques used in this work was possible to distinguish in which step the $\mathrm{N}_{2} \mathrm{O}$ and the other gaseous products are being released during the thermal decomposition.

\subsection{LC-MS/MS analysis on intermediate residues from the thermal decomposition in oxidative condition of Lornoxicam}

To further understand the mechanism of the Lornoxicam degradation, LC-MS/MS was used to analyze the residues of Lornoxicam heated in different temperatures. By means of chromatographic separation, the total ion chromatogram (TIC) of Lornoxicam before and after heating were obtained as showed in Fig.6. The presence of Lornoxicam (MW $371.8 \mathrm{Da}$ ) as main peak obtained at 7.3 minutes and $\mathrm{m} / \mathrm{z} 372\left([\mathrm{M}+\mathrm{H}]^{+}\right)$was observed in all chromatograms except for the one referred at temperature of $235^{\circ} \mathrm{C}$ (Fig. 1d), where other peak could be observed. The comparison of peak area in the chromatogram data indicated the degradation of Lornoxicam at 220 and $235^{\circ} \mathrm{C}$ (Fig. 7). However, at $180^{\circ} \mathrm{C}$ the Lornoxicam did not undergo decomposition as the peak area remains unchanged. 

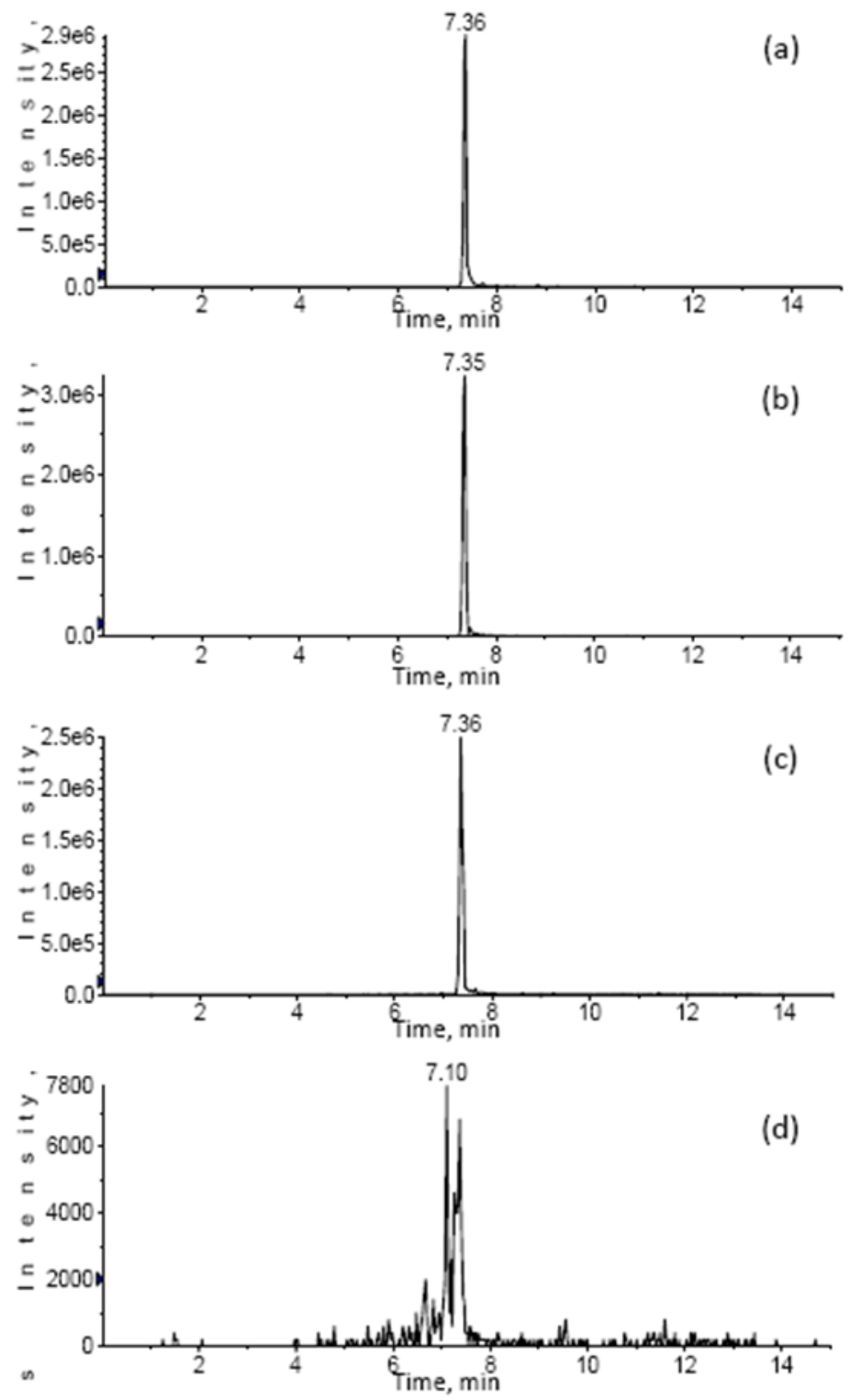

Fig. 6: TIC (total ion chromatogram) (a) unheated; (b) $180{ }^{\circ} \mathrm{C}$; (c) $220^{\circ} \mathrm{C}$ and (d) $235^{\circ} \mathrm{C}$. 


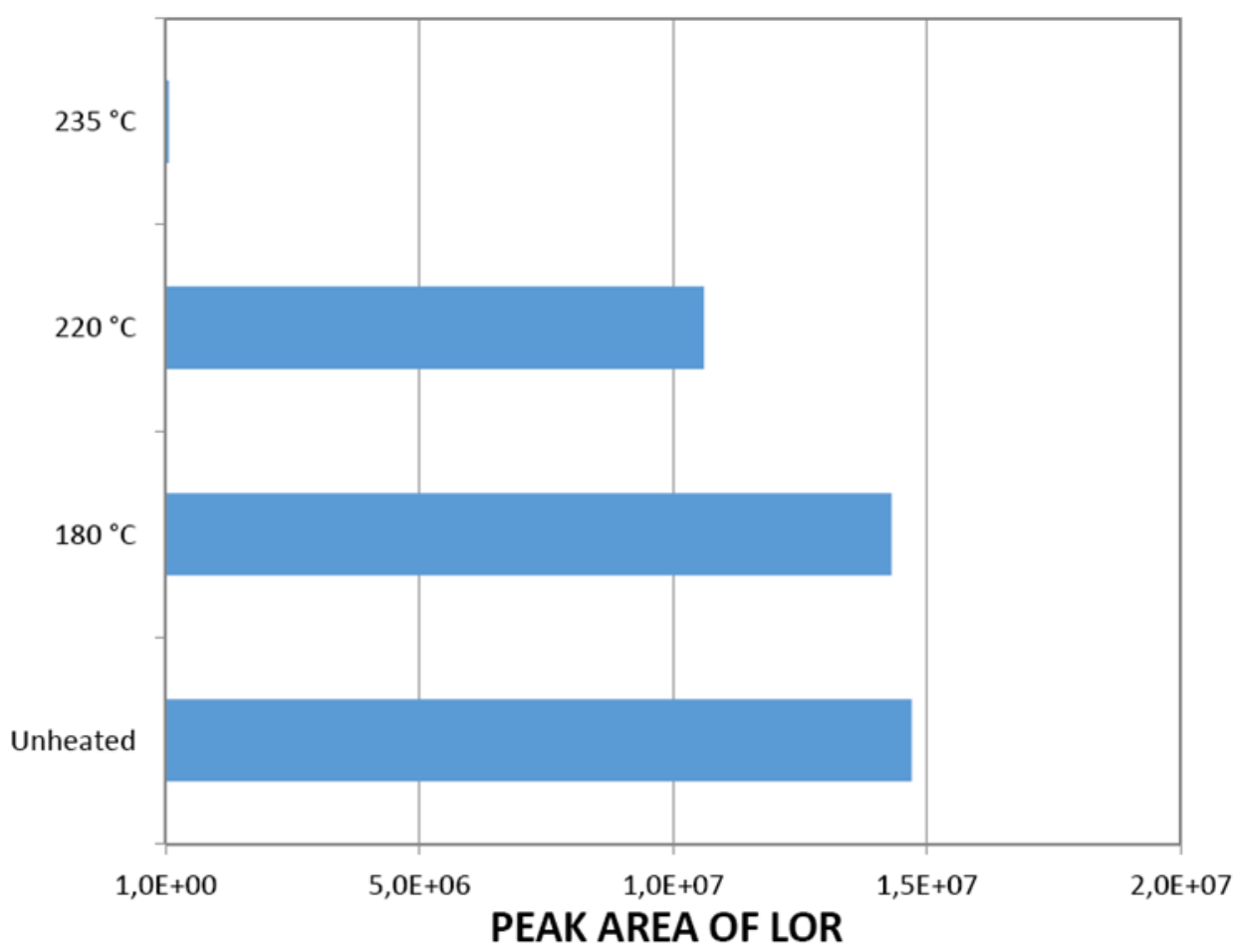

Fig. 7: Decomposition of Lornoxicam using the peak area at 7.3 minutes.

Additional peaks were observed during the LC-MS/MS experiments of samples heated at $220{ }^{\circ} \mathrm{C}$ and $235{ }^{\circ} \mathrm{C}$, which were not observed in the unheated and $180{ }^{\circ} \mathrm{C}$ samples. Table 1 shows the main detected intermediate compounds, as well as retention times and main fragment ions during thermal degradation. As can be observed three intermediate, where two intermediates compounds were obtained at $220^{\circ} \mathrm{C}$ instead of one in $235^{\circ} \mathrm{C}$, these results confirm the efficiency of decomposition in higher temperatures. To elucidate the structure of the products observed at different temperatures, and hence propose a decomposition pathway for Lornoxicam, MS/MS experiments were performed. The intermediate product detected as $m / z 336$ (MW $335 \mathrm{Da}$ ) indicates a loss of $36 \mathrm{Da}$, when compared to the initial Lornoxicam. This loss suggests the elimination of $\mathrm{HCl}$, however it was observed $\mathrm{m} / \mathrm{z}, 338$ in the same retention time (7.79 minutes) at the spectrum data, which correspond to the isotope $\mathrm{M}+2$ of the chloride $\left({ }^{35} \mathrm{Cl}\right.$ and $\left.{ }^{37} \mathrm{Cl}\right)$. Thus, the elimination of $36 \mathrm{Da}$ could be associated to the dehydrated product (double loss of 18 $\left.\mathrm{Da}\left(\mathrm{H}_{2} \mathrm{O}\right)\right)$. The main fragment obtained to the $\mathrm{m} / \mathrm{z} 336$ was $\mathrm{m} / \mathrm{z}, 121$, referred to $\mathrm{C}_{6} \mathrm{H}_{5} \mathrm{~N}_{2} \mathrm{O}^{+}$. The ion $\mathrm{m} / \mathrm{z}, 121$ is the same ion fragment obtained to Lornoxicam as mentioned in the Table 1, which confirms that the structure suffered a minimal modification and keep the main structure of the Lornoxicam. The intermediate product detected as $\mathrm{m} / \mathrm{z} 356(\mathrm{MW} 355 \mathrm{Da}$ ) presented $\mathrm{m} / \mathrm{z} 121$ as a fragment ion (referred to $\mathrm{C}_{6} \mathrm{H}_{5} \mathrm{~N}_{2} \mathrm{O}^{+}$). The loss of $16 \mathrm{Da}$, when compared to Lornoxicam was associated to the 
formation of a five member ring. Both intermediates were observed at $220{ }^{\circ} \mathrm{C}$. At $235^{\circ} \mathrm{C}$ only $\mathrm{m} / z 310$ (MW $309 \mathrm{Da}$ ) was detected as an intermediate product. The fragment ions obtained were $m / z 216\left(\mathrm{C}_{8} \mathrm{H}_{7} \mathrm{NO}_{2} \mathrm{SCl}^{+}\right)$and $95\left(\mathrm{C}_{5} \mathrm{H}_{7} \mathrm{~N}_{2}{ }^{+}\right)$. Thus all the proposal structures were confirmed by MS/MS experiments performed. The extracted ion chromatograms and fragmentation mechanisms for all intermediate products have been shown in supplementary Figures S5 and S6.

Table 1: Intermediate products obtained by LC-MS/MS analyses.

\begin{tabular}{|c|c|c|c|c|c|c|}
\hline COMPOUNDS & MW & $\left(\mathrm{g} \mathrm{mol}^{-1}\right)$ & {$[\mathbf{M}+\mathrm{H}]^{+}(m / z)$} & MS/MS & RETENTION TIME (min) & PROPOSAL STRUCTURE \\
\hline LOR & & 371 & 372 & $164,121,95$ & 7.3 & \\
\hline $\begin{array}{l}\text { Intermediate } 1 \\
220^{\circ} \mathrm{C}\end{array}$ & & 335 & 336 & 121 & 7.7 & \\
\hline $\begin{array}{c}\text { Intermediate } 2 \\
220^{\circ} \mathrm{C}\end{array}$ & & 355 & 356 & 148,121 & 9.3 & \\
\hline $\begin{array}{l}\text { Intermediate } 3 \\
235^{\circ} \mathrm{C}\end{array}$ & & 309 & 310 & 216,95 & 7.1 & \\
\hline
\end{tabular}

\section{Conclusions}

Lornoxicam is a thermally stable drug and its initial decomposition temperature is not until $205^{\circ} \mathrm{C}$. The thermal decomposition process goes through a two-stage process in both oxidant and pyrolytic atmospheres. By means of thermogravimetric techniques coupled to FTIR and MS, the investigation of the gaseous products generated during the thermal decomposition process under both atmospheric conditions was possible with $\mathrm{HCN}, \mathrm{SO}_{2}, \mathrm{COS}, \mathrm{CO}_{2}, \mathrm{~N}_{2} \mathrm{O}$ and $\mathrm{CO}$ all being observed. Hot-stage microscopy (HSM), allowed the visualization of the thermal behavior of Lornoxicam as it was heated and gave good agreement with the degradation processes observed using TG. Finally LC-MS/MS analysis of the solid residues produced at different temperatures allowed for 
the identification of the various degradation products, which suggests a very complex process of thermal decomposition of this drug.

\section{Acknowledgments}

The authors thanks University of Huddersfield CPID/CDMF, FAPESP (Proc. $n^{\circ}$ 2013/09022-7, 2017/14936-9, 2018/12463-9, 2018/24378-6 and 2008/10449-7), CNPq (Proc. 143253/2017-4 and 421469/2016-1) and CAPES foundations (Brazil) for financial support. This study was financed in part by the Coordenação de Aperfeiçoamento de Pessoal de Nível Superior - Brasil (CAPES) - Finance Code 001.

\section{References}

[1] M. Batlouni, Nonsteroidal Anti-inflammatory Drugs: Cardiovascular, Cerebrovascular and Renal Effects, Arq Brass Cardiol, 94 (4) (2010) 522-529.

[2] D. D. Gadade, D. A. Kulkarni, P. B. Rathi, S. S. Pekamwar, S. S. Joshi, Solubility Enhancement of Lornoxicam by Crystal Engineering, Indian J Pharma Sci, 79 (2) (2017) 277-286.

[3] J. Zhang, X. Tan, J. G.,W. Fan, Y. Gao, S. Qian, Characterization of two polymorphs of lornoxicam, Journal Pharm Pharmacol, 65 (2012) 44-52.

[4] M. O. Ahmed,A. A. Al-Badr Lornoxicam, in H. G. Brittain (Eds), Profiles of Drug Substances, Excipients, and Related Methodology, Elsevier Inc., 36 (2011), 205-239.

[5] K. Suresh, A. Nangia, Lornoxicam Salts: Crystal Structures, Conformations, and Solubility, Cryst. Growth Des. 14 (2014) 2945-2953.

[6] CJ. Wu, JZ. You, XJ Wang, Thermal decomposition mechanism of piroxicam, J Therm Anal Calorim, 134 (2018), 2041-2048.

[7] B. B.C. Holanda, R.T. Alarcon, R.B. Guerra, D. Rinaldo, F.C.R. Spazzini, R.A.E. Castro, G. Bannach, Investigation of thermal degradation products of mebendazole by thermal and spectroscopic analysis, J Anal Appl Pyrolysis, 135 (2018) 76-84.

[8] A.P.G. Ferreira, B.V. Pinto, É.T.G. Cavalheiro. Thermal decomposition investigation of paroxetine and sertraline, J Anal Appl Pyrolysis, 136 (2018) 232-241.

[9] R.C. Silva, J.A. Teixeira, W.D.G. Nunes, G.A.C. Zangaro, M. Pivatto, F. J.Caires, M. Ionashiro, Resveratrol: A thermoanalytical study, Food Chemistry, 237 (2017) 561565.

[10] B. Mn , R.D. Patel, P.N. Prajapati, Y.K. Agrawal, Development of forced degradation and stability indicating studies of drugs-A review, J Pharm Anal, 4 (3) (2014) 159-165.

[11] A.L.C.S. Nascimento, G.M.B. Parkes, G.P. Ashton, R.P. Fernandes, J.A. Teixeiraa, W.D.G. Nunes, M. Ionashiro, F.J. Caires, Thermal analysis in oxidative and pyrolysis conditions of alkaline earth metals picolinates using the techniques: TGDSC, DSC, MWTA, HSM and EGA (TG-DSC-FTIR and HSM-MS), J Anal Appl Pyrolysis, 135 (2018) 67-75.

[12] Y.J. Zong, W.C. Jie, W.X. Jie, The thermal decomposition mechanism of irbesartan, J Anal Appl Pyrolysis, 134 (2018) 93-101. 
[13] D. M. Patel, H. R. Shah, R. J. Patel, C. N. Patel, Preparation and characterization of Lornoxicam co-crystals, W J Pham Pharma Sci, 6 (3) (2014) 713-732.

[14] W.H. Mahmoud, G.G. Mohamed, M.M.I. El-Dessouky, Coordination modes of bidentate lornoxicam drug with some transition metal ions. Synthesis, characterization and in vitro antimicrobial and antibreastic cancer activity studies, Spec Chem Acta A: Molec BiomolecSpec 122 (2014) 598-608.

[15] J. Joshny, B.N.V. Hari, D.R. Devi, Experimental optimization of Lornoxicam liposomes for sustained topical delivery, Euro J Pharma Sci 112 (2018) 38-51.

[16] D. D. Gadade, D. A. Kulkarni, P. B. Rathi, S. S. Pekamwar And S. S. Joshi, Solubility Enhancement of Lornoxicam by Crystal Engineering , Indian J Pharma Sci 79 (2) (2017) 277-286.

[17] M.Y. Moutasim, A.N. El-Meshad, M.A. El-Nabarawi, A pharmaceutical study on lornoxicam fast disintegrating tablets: formulation and in vitro and in vivo evaluation, Drug Deliv and Transl Res 7 (2017) 450-459.

[18] S.A. Al-Suwayeh, E.I. Taha, F.M. Al-Qahtani, M.O. Ahmed, M.M. Badran. Evaluation of Skin Permeation and Analgesic Activity Effects of Carbopol Lornoxicam Topical Gels Containing Penetration Enhancer, Scientific World Journal, (2014), 1-9.

[19] A. Singh, M. Kumar, K. Pathak, $\beta$-Galactosidase mediated release characteristics of lornoxicam loaded guar gum microspheres: evaluation and product development, Pharm Biomed Res 1 (4) (2015), 12-28.

[20] R.P. Fernandes, A.L.C.S. Nascimento, A.C.S. Carvalho, J.A. Teixeira, M. Ionashiro, F.J. Caires, Mechanochemical synthesis, characterization, and thermal behavior of meloxicam cocrystals with salicylic acid, fumaric acid, and malic acid, J Therm Anal Calorim (2019).

[21] B.C. Hancock, S.L. Shamblin, Molecular mobility of amorphous pharmaceuticals determined using differential scanning calorimetry, Thermo Acta, 380 (2001) 95-107.

[22] N. Stieger, M.E. Aucamp, S.W.Zhang, M.M. De Villiers, Hot-stage optical microscopy as an analytical tool to understand solid-state changes in pharmaceutical materials, Amer Pharm Rev, 15 (2) (2012) 15.

[23] M. Nijman. Analysis of an unknow polymer sample by TGA/DSC-FTIR. METTLER TOLEDO Thermal Analysis - Information for users 46 (2017) 23-25. 